University of Nebraska - Lincoln

DigitalCommons@University of Nebraska - Lincoln

November 1999

\title{
Selective adsorption of metallocenes on clean and chemically modified $\mathrm{Si}(111)$ surfaces
}

\author{
J.-L. Lin \\ University of Wisconsin-Madison \\ H. Rauscher \\ University of Wisconsin-Madison
}

A. Kirakosian

University of Wisconsin-Madison

F.J. Himpsel

University of Wisconsin-Madison

Peter A. Dowben

University of Nebraska-Lincoln, pdowben@unl.edu

Follow this and additional works at: https://digitalcommons.unl.edu/physicsdowben

Part of the Physics Commons

Lin, J.-L.; Rauscher, H.; Kirakosian, A.; Himpsel, F.J.; and Dowben, Peter A., "Selective adsorption of metallocenes on clean and chemically modified Si(111) surfaces" (1999). Peter Dowben Publications. 35. https://digitalcommons.unl.edu/physicsdowben/35

This Article is brought to you for free and open access by the Research Papers in Physics and Astronomy at DigitalCommons@University of Nebraska - Lincoln. It has been accepted for inclusion in Peter Dowben Publications by an authorized administrator of DigitalCommons@University of Nebraska - Lincoln. 


\title{
Selective adsorption of metallocenes on clean and chemically modified Si(111) surfaces
}

\author{
J.-L. Lin, H. Rauscher, A. Kirakosian, and F. J. Himpsel ${ }^{\mathrm{a}}$ \\ Physics Department, University of Wisconsin-Madison, Madison, Wisconsin 53706-1390 \\ P. A. Dowben \\ University of Nebraska, Lincoln, Nebraska
}

(Received 16 April 1999; accepted 11 August 1999)

\begin{abstract}
Metallocene adsorption on clean $\mathrm{Si}(111)$ and $\mathrm{CaF}_{2} / \mathrm{CaF}_{1} / \mathrm{Si}(111)$ substrates has been investigated with scanning tunneling microscopy. The surface chemical composition is found to strongly change the adsorption site selectivity, leading to an enhanced edge selectivity on modified substrates. Templates with well-defined local chemical reactivity have been created via self-assembly. The selective adsorption of metallocenes on such tailored substrates facilitates patterning ordered arrays of magnetic nanowires and stripes on the single digit nanometer scale. (C) 1999 American Institute of Physics. [S0021-8979(99)01822-8]
\end{abstract}

\section{INTRODUCTION}

The rapid development in organometallic chemical vapor deposition, along with advanced light-induced chemical processing, has opened up the possibilities of fabricating metallic structures. ${ }^{1-3}$ Photofragmentation of the molecules removes organic ligands while leaving metal atoms behind on the surface, making it particularly attractive in developing ferromagnetic materials without incorporation of carbon or oxygen. ${ }^{1,3}$ On the micrometer scale, a variety of shapes and sizes of these structures has been achieved. ${ }^{1}$ Difficulties remain in reducing the size to the nanometer scale while preserving the uniformity of the structures, which is critical in applications. The continued trend of miniaturization provides a strong force for reducing the structure size. ${ }^{4}$ To that end, numerous studies including employing optical lithography, electron-beam writing, single atom manipulation with scanning tunneling microscope (STM), etc., have been made. ${ }^{1-3,5}$ Yet, it has been challenging to match the cost/performance requirements.

We are currently exploring the possibility for fabricating magnetic nanostructures on a large scale. In particular, we emphasize the selectivity of metallocene adsorption on stepped $\mathrm{Si}(111)$ surfaces as a possible route for manufacturing arrays of magnetic nanostructures. We have investigated the characteristics of the adsorption on both clean and chemically modified $\mathrm{Si}(111)$ surfaces. Templates with enhanced selectivity have been created by producing self-assembled stripe patterns of $\mathrm{CaF}_{2}$ and $\mathrm{CaF}_{1}$ on stepped $\mathrm{Si}(111)$ surfaces with a typical width of 5-10 $\mathrm{nm}$. Whether selective deposition produces the desired growth mode for nanowires could well hinge on the chemical reactivity of such a preconditioned substrate.

\section{EXPERIMENTAL METHOD}

$\mathrm{Si}(111)$ wafers with $1.1^{\circ}$ miscut towards [ $[\overline{1} 12]$ are used in the experiment. The $\mathrm{Si}(111)$ surface is cleaned following

${ }^{a)}$ Electronic mail: himpsel@comb.physics.wisc.edu the procedures reported earlier: ${ }^{6}$ high-temperature flashes up to $1250^{\circ} \mathrm{C}$ for approximately $10 \mathrm{~s}$ followed by annealing at $850^{\circ} \mathrm{C}$ for $20 \mathrm{~min}$ and slow cool down to room temperature (about $7 \mathrm{~min}$ ) at a base pressure $<1 \times 10^{-10}$ Torr. For chemical modification of the clean $\mathrm{Si}(111)$ surface, we choose to grow a $\mathrm{CaF}_{2}$ layer because of the close match of the lattice constant between deposit and substrate as well as the insulating nature of $\mathrm{CaF}_{2}{ }^{7,8}$ The $\mathrm{CaF}_{2}$ growth is conducted at a substrate temperature of $610^{\circ} \mathrm{C}$ at a growth rate of $\sim 20 \AA / \mathrm{min}$. $10 \mathrm{~s}$ annealing at $830^{\circ} \mathrm{C}$ is followed to form a $\mathrm{Si}-\mathrm{Ca}-\mathrm{F}$ interface layer with $\mathrm{CaF}_{1}$ stoichiometry, where the $\mathrm{Ca}$ atoms bond to $\mathrm{Si}^{7}$ By growing 1-2 $\mathrm{ML} \mathrm{CaF}_{2}$, the $\mathrm{CaF}_{2}$ stripes are formed at the upper step edges in regular arrays, covering the $\mathrm{CaF}_{1} / \mathrm{Si}(111)$ interface. ${ }^{7,8} \mathrm{STM}$ images are taken typically with a sample voltage of $+4 \mathrm{~V}$ and tunneling current of $0.4 \mathrm{nA}$. The positive sample voltage of $4 \mathrm{~V}$ leads to electron tunneling from the tip directly into the conduction band of $\mathrm{CaF}_{2}{ }^{7}$ Thereby, disturbing effects, such as tip crash, etc. during scanning, are avoided. STM images shown in this article are in a pseudo three-dimension presentation with steps descending from left to right.

Metallocenes, one of the organic derivatives of the transition metals, have long been of interest as precursors in growing metallic microstructures via photolytic and pyrolytic processes. ${ }^{1,2,9}$ The molecule, $(\mathrm{Cp})_{2} \mathrm{M}$, contains a metal atom (M) sandwiched between two cyclopentadienyl rings, $(\mathrm{Cp})_{2}$. The bond to the metal atom involves a $\pi$ bonded system. The molecules are highly colored, stable to hydrolysis, and many melt and evaporate without decomposition. The lowest unoccupied molecular orbit-highest occupied molecular orbit (LUMO-HOMO) gap of these metallocenes is typically in the energy range from 2.5 to $5 \mathrm{eV}^{1,10}$ The deposition of the metallocenes is conducted in the vacuum chamber with dosing pressures varying from $5 \times 10^{-8}$ to 5 $\times 10^{-6}$ Torr. STM images in Figs. 1 and 4 are taken after nickelocene exposure at room temperature. The adsorbates are nickelocene molecules. Nickelocenes are decomposed at temperatures above $100{ }^{\circ} \mathrm{C} .{ }^{11}$ STM images in Figs. 3 and 6 are taken after the substrate temperature is raised above 

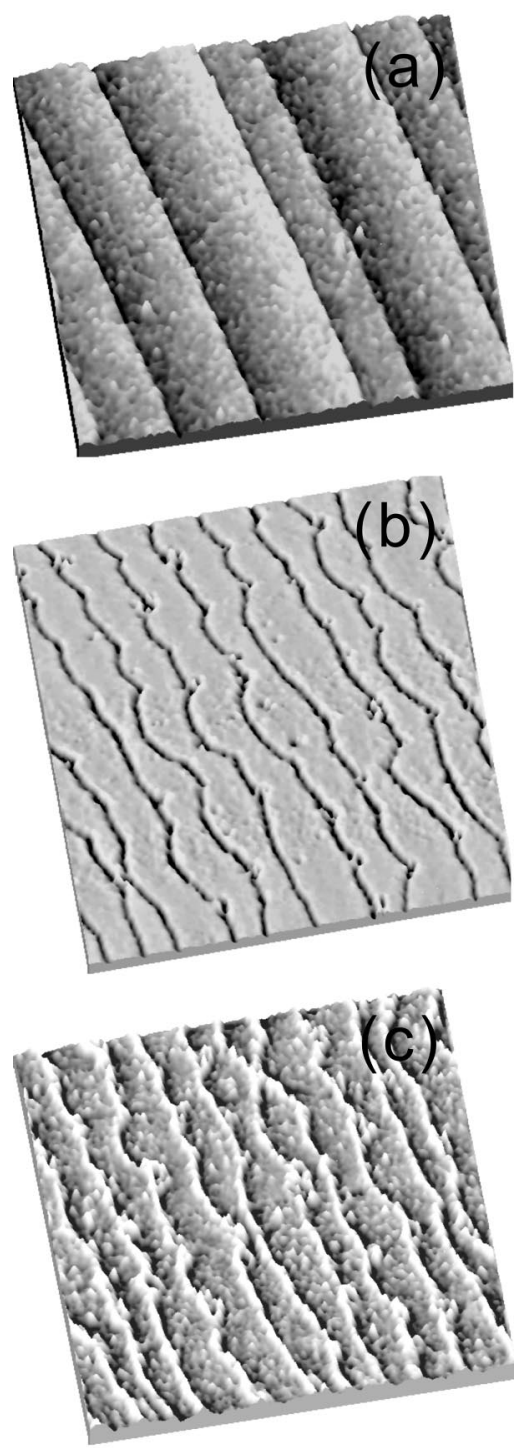

FIG. 1. (a) $\mathrm{Si}(111)$ surface covered by nickelocene at room temperature with $900 \mathrm{~L}$. STM image of $100 \times 100 \mathrm{~nm}^{2}$. (b) A single layer of $\mathrm{CaF}_{2}$ atop the $\mathrm{CaF}_{1} / \mathrm{Si}(111)$ interface with high growth rate of $70 \AA / \mathrm{min}$, causing meandering steps. STM image of $150 \times 150 \mathrm{~nm}^{2}$. (c) The substrate after nickelocene exposure at room temperature with $6 \mathrm{~L}$. STM image of 150 $\times 150 \mathrm{~nm}^{2}$.

$100{ }^{\circ} \mathrm{C}$ due to either growth or postannealing. The adsorbates shown in these two figures are nickelocene fragments.

\section{ADSORPTION SITE SELECTIVITY}

When metallocene molecules strike a clean $\mathrm{Si}(111)$ surface, they bind to surface atoms predominantly in molecular form. ${ }^{12}$ At room temperature the adsorbed molecules form a disordered layer on clean $\mathrm{Si}(111)$ surfaces. We have examined the surface with nickelocene exposure ranging from 6 to $900 \mathrm{~L}$ (Langmuir) and found no preferred molecular landing sites on this surface. Figure 1(a) is an STM image showing a $\mathrm{Si}(111)$ substrate covered by nickelocene molecules. The single height $(0.32 \mathrm{~nm})$ steps are separated by terraces of $\sim 17 \mathrm{~nm}$ wide. Steps become favorable adsorption sites when $\mathrm{Si}(111)$ surface is covered by between 1 and $2 \mathrm{ML}$ of $\mathrm{CaF}_{2}$. Figure 1(b) shows another STM image displaying a $\mathrm{Si}(111)$

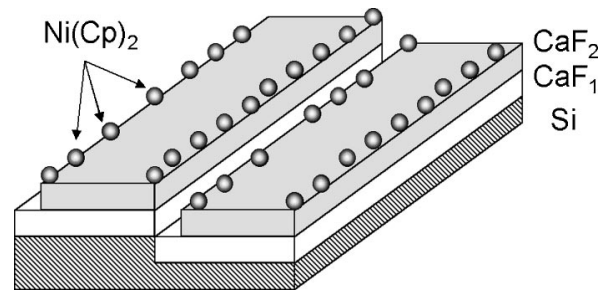

FIG. 2. Schematic diagram of a chemically modified $\mathrm{Si}(111)$ showing enhanced edge selectivity for nickelocene adsorption.

substrate overlaid by a single $\mathrm{CaF}_{2}$ layer covering the $\mathrm{CaF}_{1} / \mathrm{Si}$ interface. A substrate temperature of $610^{\circ} \mathrm{C}$ and growth rate of $70 \AA / m i n$ have been applied. Because of the relatively high $\mathrm{CaF}_{2}$ vapor flux during the growth, the modified substrate shows meandering step edges, somewhat deviating from step configurations of the underlying $\mathrm{Si}(111)$. Figure 1(c) shows the surface after nickelocene molecules are deposited. Along the upper step edge, the adsorbed nickelocene molecules form strings with a remarkable order. In contrast, particles on terraces are randomly distributed.

Different substrates exhibit different strength of the interaction between the substrate atoms and deposits. This interaction can also be influenced by the presence of steps and other defects under certain conditions. Clean $\mathrm{Si}(111)$ surfaces interact strongly with metallocene molecules. Therefore, they hardly display any selectivity at room temperature. A monolayer $\mathrm{CaF}_{2}$, on the other hand, is less reactive and exhibits weaker interactions. It allows the diffusion of molecules towards the step edge where they apparently have a higher binding energy. By chemically modifying the surface one can exercise control over the strength of the bond between the adsorbates and adsorbents. Steps and other defects, thereby, can serve as the anchors of the adsorbed molecule. In Fig. 2 we show a schematic drawing of a chemically modified substrate. With a nearly complete $\mathrm{CaF}_{2}$ layer atop a $\mathrm{CaF}_{1} / \mathrm{Si}(111)$ interface, step edges on this substrate become preferred adsorption sites for nickelocene molecules. In Fig. 3(a), we show an STM image of the modified substrate with a highly ordered step profile dictated by that of the $\mathrm{Si}(111)$ surface. We have found that the $\mathrm{CaF}_{2}$ layer never touches the lower edge of the steps under the growth conditions described earlier. The factors controlling this effect have been discussed in previous studies. ${ }^{7,8}$ After the substrate is exposed to nickelocene vapor at room temperature followed by a brief high temperature annealing, the upper step edge is decorated by a string of adsorbates guided by the steps. Voids in the $\mathrm{CaF}_{2}$ layer expose the underlying $\mathrm{CaF}_{1} / \mathrm{Si}(111)$ interface. Aggregates are clustered and aligned at the edge of these imperfect sites, exhibiting a similar adsorptive behavior. These effects are illustrated in Figs. 3(b) and 3(c). Figure 3(b) is an STM image showing the substrate after room temperature deposition followed by postannealing at $T$ $=500^{\circ} \mathrm{C}$. It displays a nearly perfect alignment of the adsorbates confined by the upper step edge. Figure 3(c) shows a similar effect owing to the defects. The lower step edge is occupied by adsorbates because the nearby $\mathrm{CaF}_{1} / \mathrm{Si}(111)$ interface was uncovered by $\mathrm{CaF}_{2}$. At postannealing temperatures above $100^{\circ} \mathrm{C}$, most remaining adsorbate on these sur- 

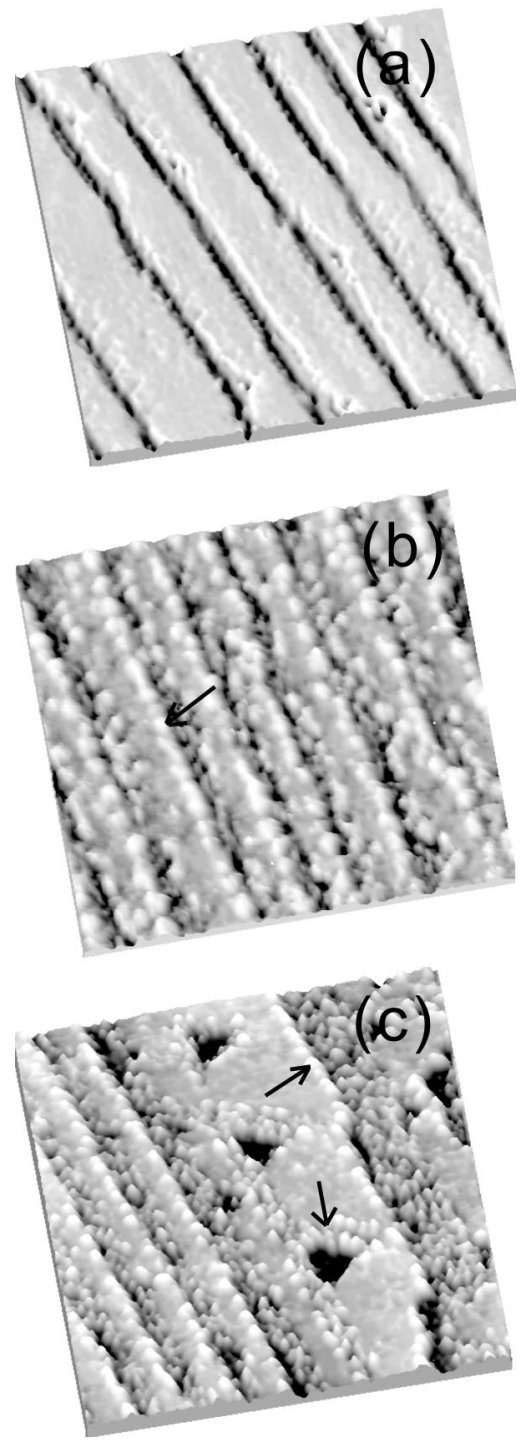

FIG. 3. (a) A nearly complete coverage of single layer $\mathrm{CaF}_{2}$ on $\mathrm{CaF}_{1} / \mathrm{Si}(111)$ with ordered step profile. STM image of $100 \times 100 \mathrm{~nm}^{2}$. (b) Strings of adsorbed nickelocene fragments are aligned along the upper edge of the steps (indicated by arrow) after room temperature adsorption followed by postannealing at $500^{\circ} \mathrm{C} .900 \mathrm{~L}$. STM image of $100 \times 100 \mathrm{~nm}^{2}$. (c) Preferred adsorption sites along the edges of voids (indicated by arrows). Room temperature exposure of $600 \mathrm{~L}$. STM image of $100 \times 100 \mathrm{~nm}^{2}$. Adsorbates on the lower edge of the steps are bound to surface atoms on a $\mathrm{CaF}_{1} / \mathrm{Si}(111)$ interface.

faces are not intact nickelocene molecules any more. They are fragments, such as nickel, acetyl cyclopropene nickel, cyclopropene nickel, and very little cyclopentadienyl nickel. ${ }^{11}$

By increasing $\mathrm{CaF}_{2}$ coverage, the chemical reactivity of the $2^{\text {nd }} \mathrm{CaF}_{2}$ layer is considerably weaker than that of the $1^{\text {st }}$ layer on top of the $\mathrm{CaF}_{1} / \mathrm{Si}(111)$ interface. Stripes of the $2^{\text {nd }}$ $\mathrm{CaF}_{2}$ layer, shown as bright regions in Fig. 4, are free of nickelocene molecules even at room temperature exposure. Molecules adsorbed on the $1^{\text {st }}$ layer of $\mathrm{CaF}_{2}$ (darker areas in Fig. 4) exhibit the characteristic edge selectivity discussed earlier.

Selective adsorption driven by the strength of the interactions is determined by the electronic structures of the de-

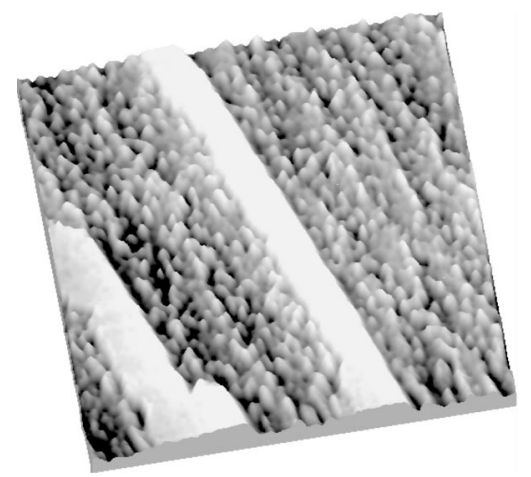

FIG. 4. The $2^{\text {nd }} \mathrm{CaF}_{2}$ layer is not chemically reactive after room temperature exposure. The bright stripes show areas covered by the $2 \mathrm{nd} \mathrm{CaF}_{2}$ layer, and are free of molecules at room temperature. $900 \mathrm{~L}$. STM image of 150 $\times 150 \mathrm{~nm}^{2}$.

posit and substrate. On clean $\mathrm{Si}(111)$, we expect a strong interaction between nickelocene and substrate. In this case, local chemical bond formation on the sites of Si dangling bonds can be expected to play a dominant role in adsorption of nickelocenes. In an earlier publication, we interpreted strong bonding between organic molecules and $\mathrm{CaF}_{1} / \mathrm{Si}(111)$ substrate in terms of energetics of the band gap of the substrate and the LUMO-HOMO gap of the adsorbate. ${ }^{13}$ Intuitively, one would expect that the chemical bonding becomes stronger as the energy overlapping of the substrate band gap and the LUMO-HOMO gap of the adsorbates increases. Meanwhile, the strong interaction between the substrate orbital and either the LUMO (if in the valance band) or HOMO (if in the conduction band) requires favorable symmetry factors. ${ }^{14}$ Accordingly, it should come as no surprise that $\mathrm{CaF}_{2}$ with a broad band gap of $12 \mathrm{eV}$ is not chemically reactive to nickelocene possessing a significantly narrower LUMO-HOMO gap of about $4-5 \mathrm{eV} .^{1,15}$

A qualitative explanation to the drastic change in the strength of the chemical reactivity of $\mathrm{CaF}_{2}$ layers with different thickness can be attempted if we use a physisorption model concerning the basic van de Waals effect. ${ }^{16}$ We estimate that the strength of the electrostatic attractive interaction between the adsorbate and adsorbent is reduced at least 8 times from the $1^{\text {st }}$ to the $2^{\text {nd }} \mathrm{CaF}_{2}$ layer. On the $2^{\text {nd }}$ layer, this attractive interaction is considerably smaller than thermal energy of $\sim 26 \mathrm{meV} .{ }^{17}$ Edge selectivity on a single $\mathrm{CaF}_{2}$ layer has been observed on substrates both at room temperature and elevated temperatures. It is well pronounced at elevated temperature of about $500{ }^{\circ} \mathrm{C}$ when the terrace diffusion of the adsorbates is quite rapid. Once the adsorbates arrive at the step edge, they have to overcome a diffusion barrier for descending motion across the steps. Apparently, this hindrance is caused by the adsorbates at the lower edge, which are inert and perhaps repulsive to the incoming molecules. Diffusion barriers for crossing steps have been reported previously for other systems. ${ }^{4,18}$ The molecular aggregates are also found to be clustered along the step edge, suggestive of an attractive intermolecular interaction. ${ }^{19}$ It is also indicative of the formation of an in-plane surface dipole oriented perpendicular to the step edge, leading to an attractive interaction between the adsorbates and step. ${ }^{19}$ This is 


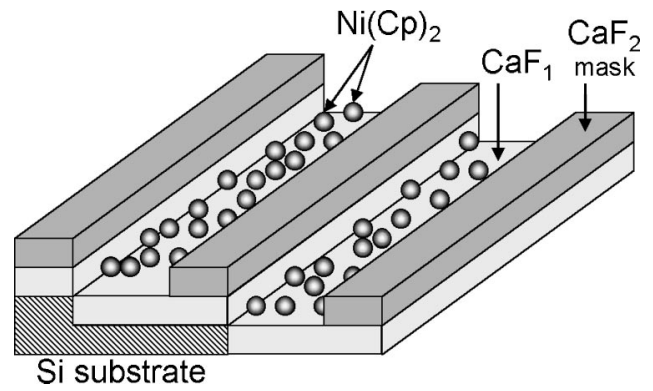

FIG. 5. Schematic diagram of $\mathrm{CaF}_{2} / \mathrm{CaF}_{1} / \mathrm{Si}(111)$ substrate for selective nickelocene adsorption.

likely another important factor giving rise to the enhanced edge selectivity.

\section{NANOWIRE PATTERNING}

It is conceivable that the selective adsorption on a chemically modified substrate can facilitate manufacturing of metallic structures down to the single digit nanometer scale. The option for surface modification, however, is limited by the growth modes that can be achieved. Fortunately, our choice of the combination of $\mathrm{CaF}_{2} / \mathrm{CaF}_{1} / \mathrm{Si}(111)$ assures the growth of self-assembled nanostripes, in addition to the distinctly different band gap of $\mathrm{CaF}_{2}$ and $\mathrm{CaF}_{1}, \sim 12 \mathrm{eV}$ vs 2.4 $\mathrm{eV}$. The accumulated knowledge now puts us in a position to devise a template containing precisely arranged stripes with alternating local chemical reactivity with a periodicity of 10-20 nm. ${ }^{7}$ We expect the metallocene molecules to be rejected in regions covered by $\mathrm{CaF}_{2}$ while being accepted in places with $\mathrm{CaF}_{1}$. The width of the $\mathrm{CaF}_{2}$ stripes can be finely adjusted in the range of a few $\mathrm{nm}$, whereas the order of the structures is self-organized during the growth. The spacing between the $\mathrm{CaF}_{2}$ stripes can also be accurately controlled. Figure 5 is a schematic drawing illustrating the selective nickelocene adsorption on such a tailored substrate. The stripes are $\mathrm{CaF}_{2}$ and trenches are $\mathrm{CaF}_{1}$. The $\mathrm{CaF}_{1}$ trenches are adsorption sites of nickelocene molecules, while the $\mathrm{CaF}_{2}$ stripes are masks shaping the adsorbates with a desired pattern. Figure 6(a) is an STM image of an ensemble of $\mathrm{CaF}_{2}$ stripes grown on a $\mathrm{Si}(111)$ surface with a $\mathrm{CaF}_{1} / \mathrm{Si}$ interface. We expose the substrate to nickelocene vapor at temperature of $500{ }^{\circ} \mathrm{C}$, and the adsorbates are selectively deposited in the $\mathrm{CaF}_{1}$ trenches. Because bonding to $\mathrm{CaF}_{2}$ is very weak, no adsorption takes place at the elevated growth temperature [see Fig. 6(b)]. In another experiment, we manage to utilize $\mathrm{CaF}_{2}$ stripes as masks upon postannealing at $T=600^{\circ} \mathrm{C}$ while depositing molecules at room temperature. As shown in Fig. 6(c), the $\mathrm{CaF}_{2}$ stripes are free of adsorbates, resulting from thermal desorption of nickelocenes. We note that at elevated substrate temperature, most adsorbates are nickelocene fragments. ${ }^{11}$ We have also found similar adsorptive behavior of several other metallocenes, such as ferrocene, etc.

\section{SUMMARY AND OUTLOOK}

In summary, we observe changes in chemical reactivity of the substrate as we change the chemical composition of
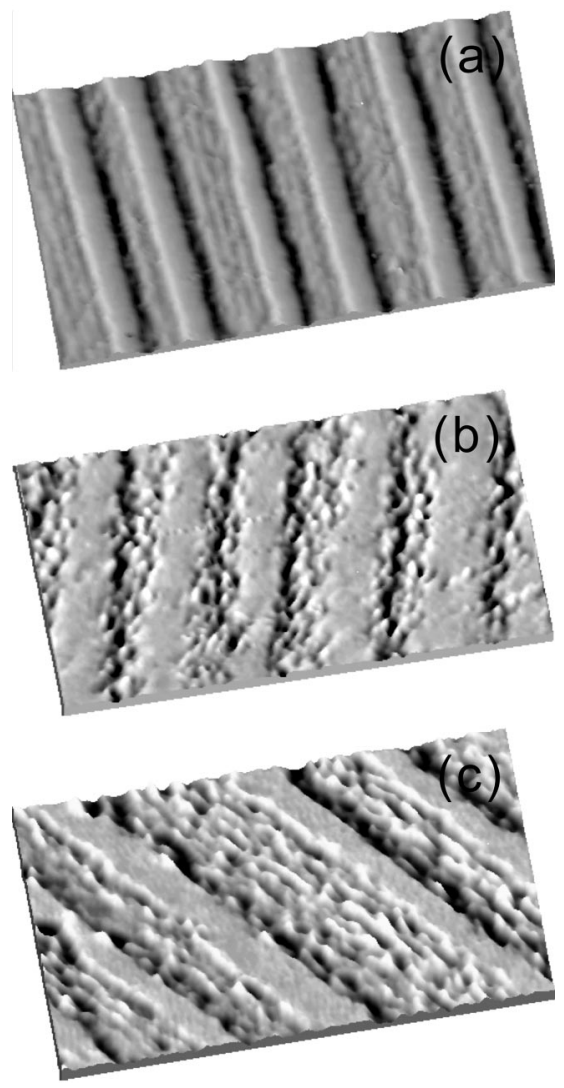

FIG. 6. (a) $\mathrm{CaF}_{2} / \mathrm{CaF}_{1} / \mathrm{Si}$ (111) substrate before deposition. The width of $\mathrm{CaF}_{2}$ stripes is $\sim 5.6 \mathrm{~nm}$, and $\mathrm{CaF}_{1}$ trenches is $\sim 12 \mathrm{~nm}$. STM image of $90 \times 50 \mathrm{~nm}^{2}$. (b) Selective adsorption on $\mathrm{CaF}_{2} / \mathrm{CaF}_{1} / \mathrm{Si}(111)$ substrate by exposing the substrate to nickelocene $(600 \mathrm{~L})$ at substrate temperature of $500{ }^{\circ} \mathrm{C}$. The $\mathrm{CaF}_{2}$ stripes are free of nickelocenes at elevated substrate temperatures. STM image of $80 \times 50 \mathrm{~nm}^{2}$. (c) Similar result is obtained upon postannealing at $600^{\circ} \mathrm{C}$. Room temperature exposure of $6 \mathrm{~L}$. STM image of $70 \times 50 \mathrm{~nm}^{2}$

the surface. By varying the coverage of $\mathrm{CaF}_{2}$ on $\mathrm{Si}(111)$, we are able to achieve selective adsorption of metallocenes with a desired pattern. Clean $\mathrm{Si}(111)$ displays a strong chemical reactivity, leading to a disordered layer of metallocene adsorbates at room temperature. Strong bonding on a $\mathrm{CaF}_{1} / \mathrm{Si}(111)$ interface is also observed, presumably arising from the intermingling of the charge density of the adsorbates and substrate. In contrast, bonding to $\mathrm{CaF}_{2}$ is very weak. Increasing $\mathrm{CaF}_{2}$ coverage to more than $2 \mathrm{ML}$ reduces the reactivity of the substrate significantly, so that the $2^{\text {nd }}$ $\mathrm{CaF}_{2}$ layer rejects metallocene molecules even at room temperature. We demonstrate a method to pattern onedimensional metallic structures on the scale of a few nanometers on self-assembled $\mathrm{CaF}_{2} / \mathrm{CaF}_{1} \mathrm{Si}(111)$ substrate with well defined local chemical reactivity. As the modern technology of fabricating nanostructure has been driven to the atomic scale, such patterning is expected to play a major role in producing fine structures. A conventional patterning involves transferring a lithographically defined image in a mask on top of the substrate with a typical structure size on the micrometer scale. The patterning by means of selective adsorption has shown great potentials to overcome the limitation of traditional method in reducing the structure size. We note that most adsorbed clusters are not intact metal- 
locene molecules at elevated temperatures when selective adsorption is remarkable. To ensure the growth of magnetic nanowires without carbon contamination, we need to focus on selective adsorption at room temperature. Recently, we have obtained molecular adsorption of strings of metallocenes by utilizing edge selectivity at room temperature. ${ }^{20}$ The results have shown promises in pursuing parallel fabrication of ordered arrays of magnetic nanowires.

\section{ACKNOWLEDGMENTS}

We thank D. Y. Petrovykh, Dr. J. Viernow, and Dr. T. A. Jung for many useful discussions. This work is supported by NSF under Award Nos. DMR-9624753, DMR-9632527, and DMR-9815416.

${ }^{1}$ Welipitiya, C. N. Borca, C. Waldfried, C. Hutching, L. Sage, C. Woodbridge, and P. A. Dowben, Surf. Sci. 393, 34 (1997); D. Welipitiya, C. Waldfried, C. N. Borca, P. A. Dowben, N. M. Boag, H. Jiang, I. Gobulukoglu, and B. W. Robertson, ibid. 418, 466 (1998).

${ }^{2}$ D. J. Enrlich and J. Y. Tsao, J. Vac. Sci. Technol. B 1, 969 (1983); R. M. Osgood and T. F. Deutch, Science 27, 709 (1985); J. V. Armstrong, A. A. Burk, Jr., J. M. Coey, and K. Moorjani, Appl. Phys. Lett. 50, 1231 (1987).

${ }^{3}$ M. A. Henderson, R. D. Ramsier, and J. T. Yates, Jr., J. Vac. Sci. Technol. A 9, 1563 (1991); A. D. Kent, S. von Molnár, S. Gider, and D. D. Awshalom, J. Appl. Phys. 76, 6656 (1994).

${ }^{4}$ See, F. J. Himpsel, J. E. Ortega, G. J. Mankey, and R. F. Willis, Adv. Phys. 47, 511 (1998) and references therein.

${ }^{5}$ S. T. Yau, D. Saltz, A. Wriekat, and M. H. Nayfeh, J. Appl. Phys. 69, 2970 (1991); E. E. Ehrichs, W. F. Smith, and A. L. de Lozanne, Ultramicroscopy 42-44, 1438 (1992); A. D. Kent, T. M. Shaw, S. von Molnár, and D. D. Awshalom, Science 262, 1249 (1993); D. D. Saulys, A. Ermakov, E. L. Garfunkel, and P. A. Dowben, J. Appl. Phys. 76, 7639 (1994); T. M. H. Wong, S. J. O'Shea, A. W. McKinnon, and M. E. Welland, Appl. Phys. Lett. 67, 786 (1995); W. W. Pai, J. Zhang, J. F. Wendelken, and R. J. Warmack, J. Vac. Sci. Technol. B 15, 785 (1997).

${ }^{6}$ J. Viernow, J.-L. Lin, D. Y. Petrovykh, F. M. Leibsle, F. K. Men, and F. J. Himpsel, Appl. Phys. Lett. 72, 948 (1998); J.-L. Lin, D. Y. Petrovykh, J. Viernow, F. K. Men, D. J. Seo, and F. J. Himpsel, J. Appl. Phys. 84, 255 (1998)
${ }^{7}$ J. Viernow, D. Y. Petrovykh, A. Kirakosian, J.-L. Lin, F. K. Men, D. J. Seo, M. Henzler, and F. J. Himpsel, Phys. Rev. B 59, 10356 (1999); J. Viernow, D. Y. Petrovykh, F. K. Men, A. Kirakosian, J.-L. Lin and F. J. Himpsel, Appl. Phys. Lett. 74, 2125 (1999); D. Y. Petrovykh, J. Viernow, J.-L. Lin, F. M. Leibsle, F. K. Men, A. Kirakosian, and F. J. Himpsel, J. Vac. Sci. Technol. A 17, 1415 (1999).

${ }^{8}$ R. M. Tromp and M. C. Reuter, Phys. Rev. Lett. 61, 1756 (1988); R. F. C. Farrow, in The Chemical Physics of Solid Surfaces and Heterogeneous Catalysis, edited by D. A. King and D. P. Woodruff, Vol. 5, p. 369 (Elsevier, Amsterdam, 1988); M. A. Olmstead, in Heteroepitaxial Systems, edited by A. W. K. Liu and M. Santos, Chap. 5 (World Scientific, Singapore, 1998).

${ }^{9}$ See for example R. Zaoni, M. N. Piancastelli, M. Marsi, and G. Margaritondo, J. Electron Spectrosc. Relat. Phenom. 57, 199 (1991).

${ }^{10}$ P. A. Dowben, C. Waldfried, T. Komesu, D. Welipitiya, T. McAvoy, and E. Vescovo, Chem. Phys. Lett. 283, 44 (1998).

${ }^{11}$ P. A. Dowbew (unpublished).

${ }^{12} \mathrm{On} \mathrm{Ag}$ and $\mathrm{Cu}$ surfaces, the molecular adsorption of nickelocene has been confirmed. See Ref. 1. The molecular adsorption is also expected on $\mathrm{Si}$, because $\mathrm{Si}(111)$ is chemically reactive.

${ }^{13}$ H. Rauscher, T. A. Jung, J.-L. Lin, A. Kirakosian, F. J. Himpsel, U. Rohr, and K. Müllen, Chem. Phys. Lett. 303, 363 (1999).

${ }^{14}$ T. B. Grimley, in The Chemical Physics of Solid Surfaces and Heterogeneous Catalysis, edited by D. A. King and D. P. Woodruff, Vol. 2, p. 333 (Elsevier, Amsterdam, 1983).

${ }^{15}$ S. Evans, M. L. H. Green, B. Jewitt, A. F. Orchard, and C. F. Pygall, J. Chem. Soc., Faraday Trans. 2 68, 1847 (1972); C. Cauletti, J. Green, M. Kelly, P. Powell, J. van Tilborg, J. Robbins, and J. Smart, J. Electron Spectrosc. Relat. Phenom. 19, 327 (1980).

${ }^{16}$ A. Zangwill, Physics at Surfaces (Cambridge University Press, Cambridge, 1988).

${ }^{17}$ An attractive electrostatic interaction arising from the basic van de Waals interaction has been estimated in the range of $40-50 \mathrm{meV}$ for the $1^{\text {st }} \mathrm{CaF}_{2}$ layer. See Ref. 16.

${ }^{18}$ T. A. Jung, Y. W. Mo, and F. J. Himsel, Phys. Rev. Lett. 74, 1641 (1995); D. Y. Petrovykh, F. J. Himpsel, and T. A. Jung, Surf. Sci. 407, 189 (1998).

${ }^{19}$ X. Chen, E. R. Frank, and R. Hamers, J. Vac. Sci. Technol. B 14, 1136 (1996).

${ }^{20}$ J.-L. Lin, A. Kirakosian, D. Y. Petrovykh, H. Rauscher, and F. J. Himpsel (unpublished). 